\title{
CHASSIS FRAME DESIGN AND ANALYSIS BASED ON FORMULA SAE JAPAN
}

\author{
IRSYADI YANI ${ }^{1}$, AMIR ARIFIN ${ }^{1}$, AHMAD IRHAM JAMBAK ${ }^{1}$, \\ GUNAWAN $^{1 *}$, DENDY ADANTA ${ }^{1}$, BARLIN ${ }^{1}$ \\ ${ }^{I}$ Dept. of Mechanical Engineering, Faculty of Engineering, Universitas Sriwijaya, South Sumatera, \\ Indonesia \\ *Corresponding author: gunawan@ unsri.ac.id
}

(Received: 21 April 2021; Accepted: 29 June 2021; Published on-line: 1 July 2021)

\begin{abstract}
Formula Society of Automotive Engineers (FSAE) is a competition where the students design, build, and race the formula-style car. In this competition, the regulation stringent for the safety of participants. Chassis is one of the regulated parts among the other parts. This paper examines design process followed by chassis analysis by using Solidworks 2018 and Abaqus/CAE 6.14 software. The analysis process is carried out with Static Vertical Test, Torsional Stiffness Test, and Crash Impact Test using a safety standard in the form of a safety factor that must be more than 1 (SF> 1) to ensure the safety of the driver. The aim is to obtain an optimum final design based on FSAE Japan regulation as a reference for the Universitas Sriwijaya electric car team, namely Sriwijaya Eco in making the framework for the upcoming electric formula car.
\end{abstract}

KEY WORDS: FSAE, chassis design, safety factor

\section{INTRODUCTION}

An electric car is a car that moves entirely using electric energy [1-3]. The electrical energy is stored in a battery in the form of electric potential. The electric potential will drive the electric motor so that the car can moves accordingly. The chassis frame is one part of the electric formula car that needs to be designed [4, 5]. Space Frame is commonly used for this purpose. This frame must meet several requirements, including being sturdy, capable of bearing vehicle loads and made with a lightweight construction yet still able to meet the FSAE Japan regulatory standards itself. The strength of the frame is affected by many factors such as design optimization, material selection, and quality of the welds on each joint [6].

Universitas Sriwijaya has a Semi-Autonomous Club engaged in automotive research including electric car development, namely Sriwijaya Eco. Sriwijaya Eco has 2 main competitions as a target to participate which are the Indonesian Electric Car Competition (KMLI) for the national level and the Formula SAE Japan (FSAEJ) for the international level. Until this paper is made, the target that has just been achieved is KMLI while the FSAEJ remains unreached.

One of the main obstacles of the Sriwijaya Eco Electric Car Team in competing for FSAEJ is the inadequacy of the electric car frame with FSAEJ regulatory standards. Thus, the purpose of this study is to design a chassis frame for an electric formula car based on the Formula SAE Japan regulations, which is then simulated using the software [7]. Hence, the benefit that can be obtained from this paper is getting a frame design that can be used as a scientific reference and advice for the Sriwijaya Eco team specifically on the electric formula car frame. 


\section{MATERIALS AND METHOD}

\subsection{Tools}

This study used a laptop and 2 software, namely Solidworks 2018 and Abaqus / CAE 6.14. The laptop used has the following specifications (Table 1):

Table 1: Laptop Specifications

\begin{tabular}{|c|c|}
\hline & Specification \\
\hline Code & Lenovo Ideapad Y700 \\
\hline \multirow[t]{2}{*}{ Display device } & Intel® HD Graphics 530 \\
\hline & 8233MB Approx. total memory \\
\hline \multirow[t]{2}{*}{ Render device } & NVIDIA GeForce GTX 960M \\
\hline & 12161MB Approx. total memory \\
\hline Opperating system & Windows Home 64 bit pre-installed \\
\hline Processor & Intel® Core ${ }^{\mathrm{TM}}$ i7-6700HQ CPU @ 2.60GHz \\
\hline
\end{tabular}

\subsection{Chassis Design}

In designing an electric car frame with FSAE standards, it is necessary to ascertain what considerations will be taken into account. those considerations are [4]:

- Compliance to regulations

- Functionality

- Durability, and

- Weight.

\subsection{Simulation Analysis}

\subsubsection{Safety Factor}

Safety factor is a reference for safety standards in the design process [8]. The safety factor is based on the Von Mises value of the yield stress or the ultimate stress of a material. The design results are considered safe if the test results on the safety factor have exceeded number 1. The safety factor is formulated as follows $[9,10]$ :

$$
n_{f}=\frac{s_{a}}{\sigma_{a}}
$$

where $\mathrm{n}_{\mathrm{f}}$ is safety factor, $\mathrm{S}_{\mathrm{a}}$ is ultimate stress, and $\sigma_{\mathrm{a}}$ is actual stress.

\subsubsection{Static Vertical Load dan Fixed Position}

The Static Vertical Bending Test aims to determine the strength of the frame against loads in the form of heavy objects on the frame including the heavy load of the car driver himself, the position of the load and the fixed position can be seen in the Fig. 1 [7]. Static vertical load is formed due to the load on the frame including the driver inside. The mass possessed by these objects generating a gravitational force as a result of Earth's gravity. This can be calculated using the following formula:

$$
w=m \cdot g
$$

where m: weight, m: mass, and g: gravity. The amount of weight will be used as a static load in the simulation process. 


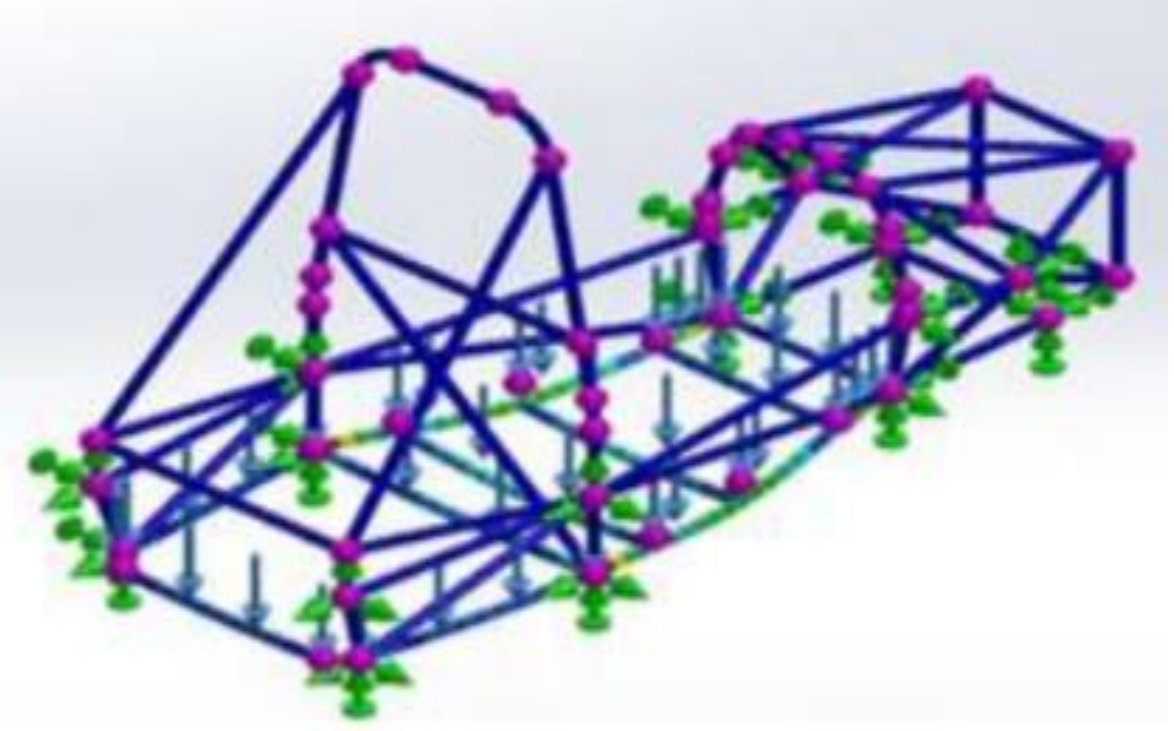

Fig. 1. Positions of forces and fixed points positions of forces and fixed points [7]

The maximum stress (max. Stress) and maximum displacement (max. Displacement) data will be analyzed. In this simulation, the chassis is expected to experience elastic deformation to return to its original shape. Thus, then the safety factor formula will be as follows:

$$
S_{f}=\frac{\sigma_{y}}{\sigma_{\operatorname{Max}}}
$$

where $S_{\mathrm{f}}$ is safety factor, $\sigma_{\mathrm{y}}$ is yield stress, and $\sigma_{\max }$ is max stress.

\subsubsection{Torsional Load dan Fixed Geometry}

Torsional Stiffness Test aims to determine the level of how good the chassis to maintain the original shape when twisted [11], the position of the load and the fixed position can be seen in the Fig. 2.

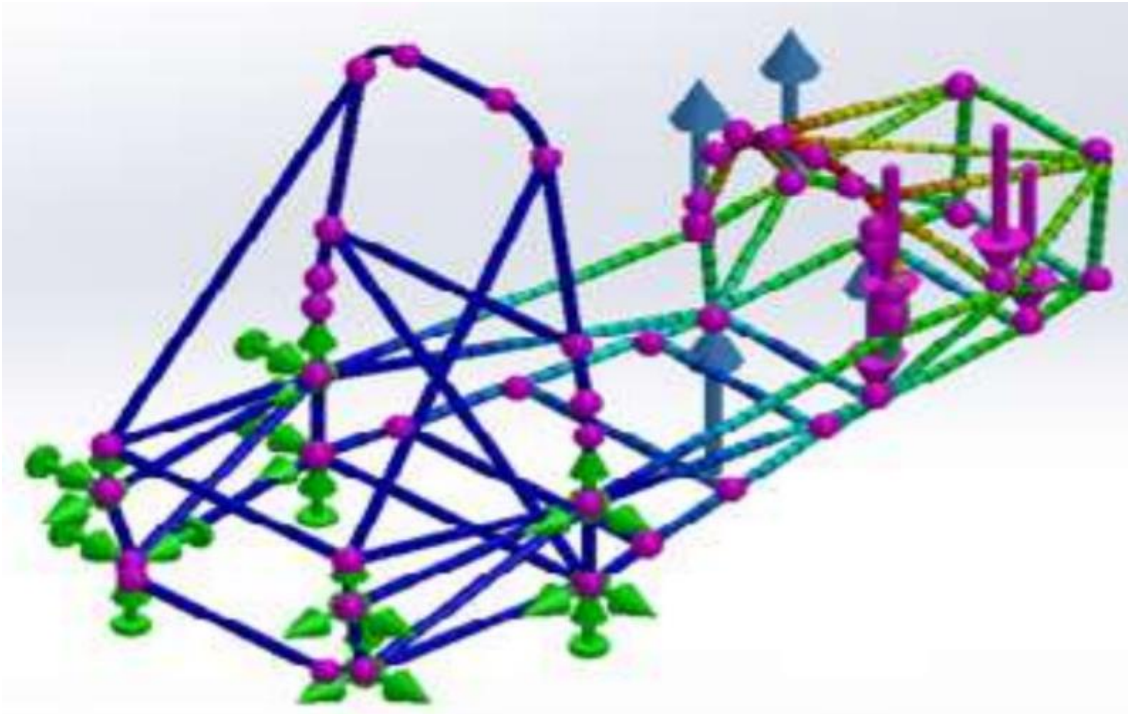

Fig. 2. Positions of forces and fixed points of torsional stiffness test [11] 
The load is formed as a result of the vehicle cornering at high speed. There is no data yet on how much load the FSAE car experienced when cornering. To add some perspective, F1 cars generally experience loads of $4 \mathrm{G}$ to $6 \mathrm{G}$ when cornering. Indeed, the Formula SAE car will not experience that much load. However, to ensure the safety of this simulation, the torsional load of $4 \mathrm{G}$ will also be given to the frame. The amount of torsional load can be calculated using the following equation:

$$
\tau=m \cdot g \cdot s
$$

where $\tau$ is torsional load, and $\mathrm{s}$ is length scale.

The maximum stress (max. Stress) and maximum displacement (max. Displacement) data will be analyzed. In this simulation, the chassis is expected to experience elastic deformation to return to its original shape. Thus, then the safety factor formula will be the same as Static Vertical Bending Test (Equation 3).

After the frame is confirmed to have a safety factor accordingly to the design concept, The Torsional Stiffness $(K)$ will be calculated. The data of displacement $(\Delta y)$ will be used to obtain $K$ using the following equation:

$$
K=\frac{F_{s} L}{\tan ^{-1}\left(\frac{\Delta y_{1}+\Delta y_{2}}{2 L}\right)}
$$

where $\mathrm{k}$ is torsional stiffness, $\mathrm{F}_{\mathrm{s}}$ is force, $\Delta \mathrm{y}$ is displacement, and $\mathrm{L}$ is length. Fig. 3 is schematic analysis Equation 5.

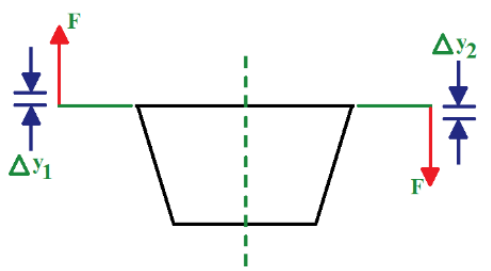

Fig. 3. 2D Torsional Stiffness Test Scheme [7]

\subsubsection{Torsional Load dan Fixed Geometry}

The dynamic load is a load that changes in respect of time [7]. The dynamic load that will be analyzed in this scenario is an Impact Load. The load generated by crushing an object (chassis frame) with a certain velocity (v) to another object which in this case is assumed to be rigid. The chassis of the car stores kinetic energy $\left(E_{k}\right)$ when it is traveling at a certain velocity. The amount of the kinetic energy can be calculated using the following formula:

$$
E_{k}=\frac{m v^{2}}{2}
$$

where Ek is kinetic energy, and $\mathrm{v}$ is velocity.

The frame that is designed must have an adequate level of strength. In addition to being a support structure for all car components, the frame also functions as a driver's protector in the event of a collision. A strong frame can minimize the injuries that a driver will experience after a collision. The purpose of the simulation is to determine the strength level of the frame when given an extreme load. Since the frame is not expected to maintain the original shape after the impact, the safety factor formula will be as follows:

$$
S_{f}=\frac{\sigma_{T}}{\sigma_{\operatorname{Max}}}
$$

where $\sigma_{\mathrm{T}}$ is ultima stress. 


\section{RESULT AND DISCUSSION}

\subsection{Final Design}

The final design of the chassis shown as in Fig. 4 and Table 2 and 3 are detail properties of the object.
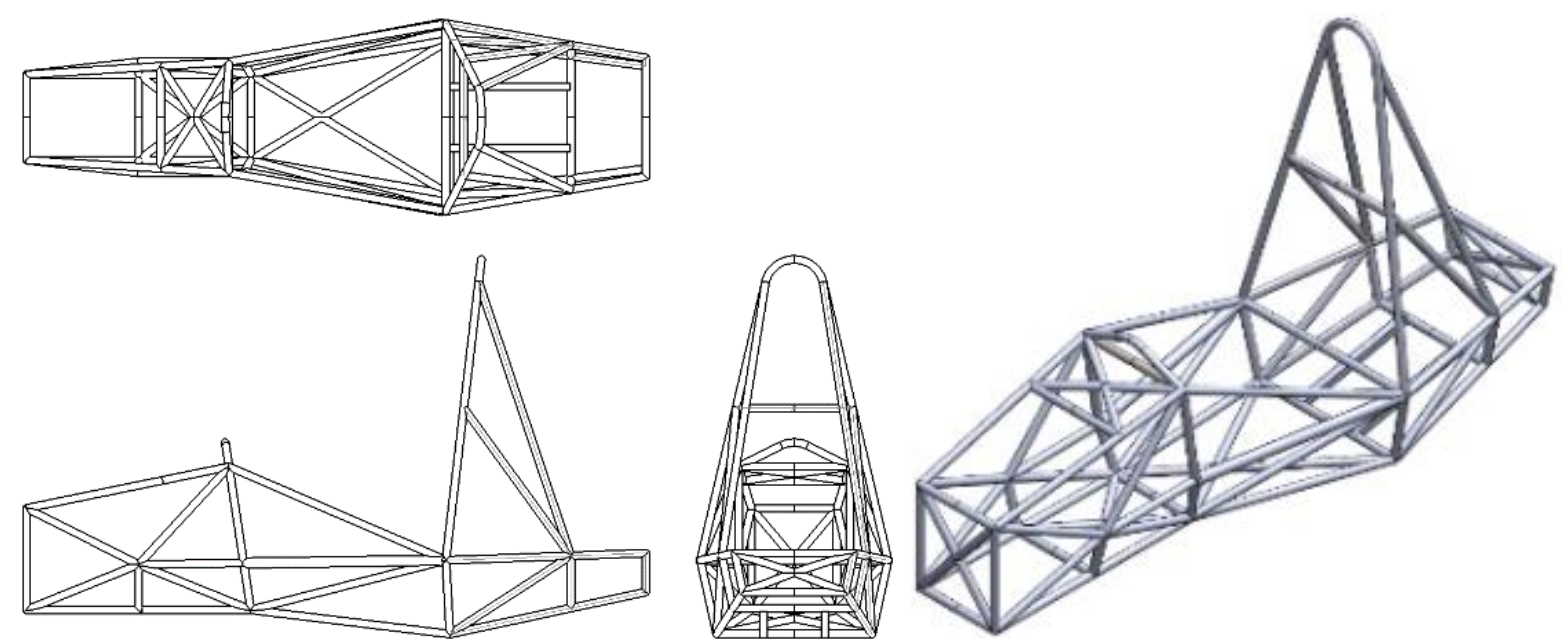

a. Top, side, and front view

b. Isometry view

Fig. 4. Chasis body

Table 2: Details and specification of chassis design

\begin{tabular}{lc}
\hline & Details and Specification \\
\hline Material & STKM11A / JIS3445 \\
Dimension & Length: $2144 \mathrm{~mm}$ \\
& Width: $660 \mathrm{~mm}$ \\
Mass & Height: $1290 \mathrm{~mm}$ \\
Frame Joint & $48.9 \mathrm{~kg}$ \\
Steel Pipe Dimension & Welded \\
\hline
\end{tabular}

Table 3: Steel pipe dimensions

\begin{tabular}{ll}
\hline \multicolumn{1}{c}{ Sections } & Outer Diameter x Thickness \\
\hline $\begin{array}{l}\text { Main hoop, front hoop } \\
\text { Side Impact Structure bulkhead, hoop }\end{array}$ & $1 \times 0.095$ inch \\
Bulkhead & $.375 \times 0.047$ inch \\
Upper Side Impact Structure & .3750 .00 \\
\hline
\end{tabular}

\subsection{Static Vertical Bending Test}

\subsubsection{Static Load}

The load calculated using Equation 2. In this test, the load is not evenly distributed. So, it is necessary to determine the amount of load at a certain point on the frame with the following assumptions:

- Body weight

- Driver weight $: 150 \mathrm{~N}$

$: 700 \mathrm{~N}$

- Electrical components

\section{$: 1200 \mathrm{~N}$}


The schematic of boundary condition can be seen in Fig. 5 .

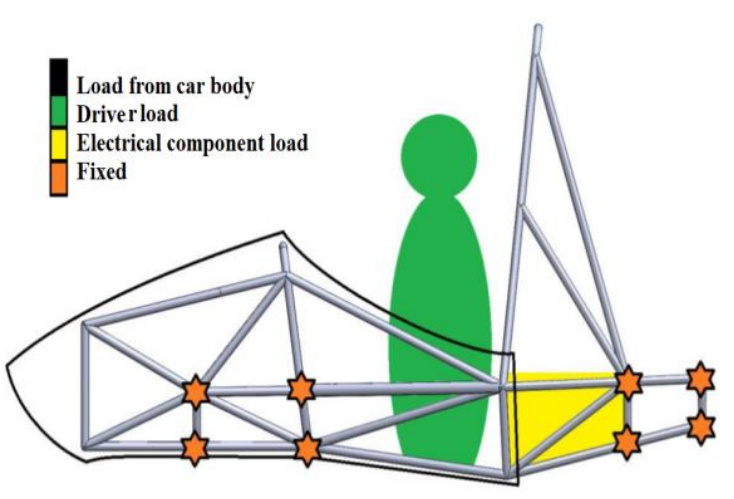

a. Boundary condition position assumption

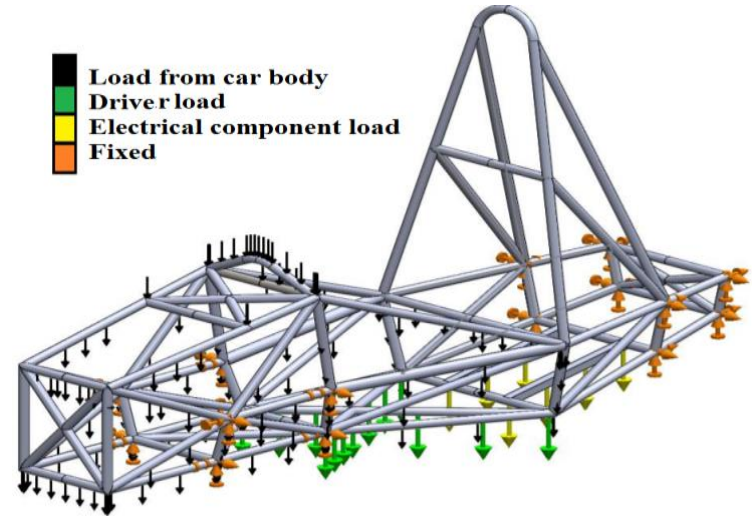

b. Boundary condition position

Fig. 5. Boundary condition

\subsubsection{Mesh Convergency}

The mesh convergency is carried out by using a sample of the frame that has max. stress from the simulation results by meshing automatically. Shown in the following Fig. 6:

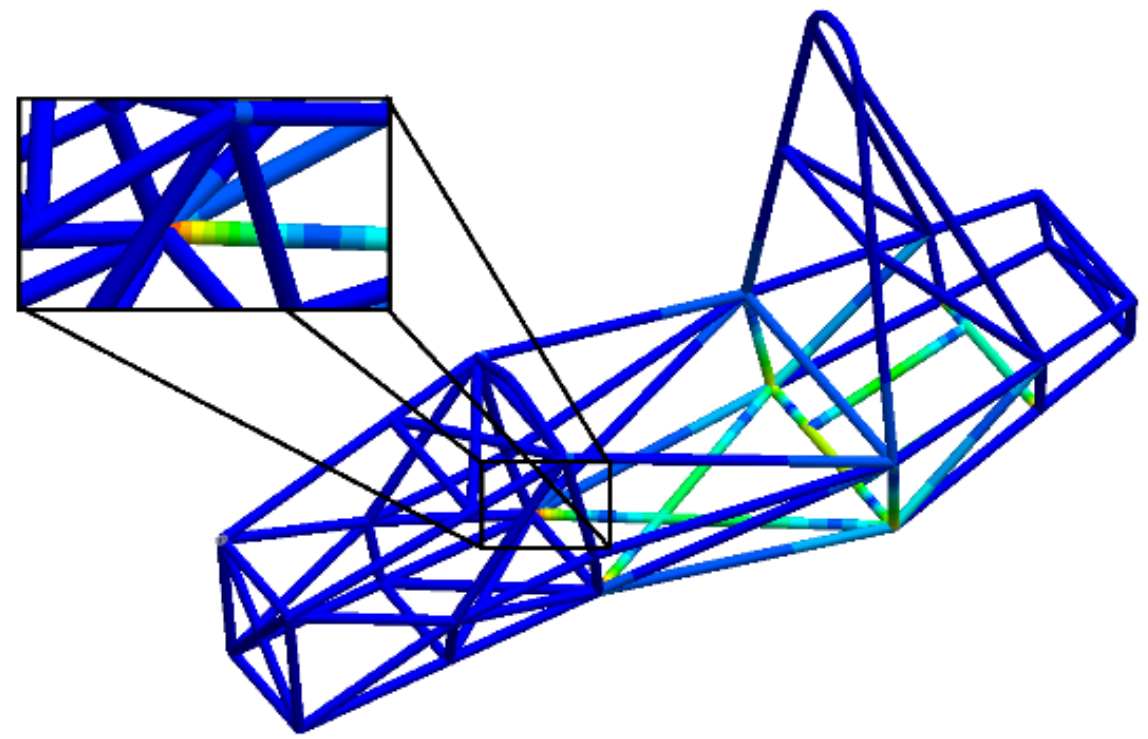

Fig. 6. Static vertical bending test critical stress point

The mesh size of the sample where the critical stress occurs is regulated in order to obtain a convergent maximum stress (max. Stress). The results of the mesh convergence test can be seen in the following Table 4:

Table 4: Static vertical bending test mesh convergency

\begin{tabular}{ccccc}
\hline Mesh Number (n) & $\begin{array}{c}\text { Elapsed Time } \\
(\mathbf{s})\end{array}$ & Total Elements & Max. Stress $\left(\mathbf{N} / \mathbf{m}^{\mathbf{2}}\right)$ & \% Dev. \\
\hline 5 & 13 & 574 & $3.10978 \times 10^{7}$ & - \\
10 & 13 & 579 & $3.10922 \times 10^{7}$ & 0.018 \\
20 & 14 & 589 & $3.10964 \times 10^{7}$ & 0.014 \\
40 & 6 & 609 & $3.10982 \times 10^{7}$ & 0.005 \\
\hline
\end{tabular}


Repetitions were carried out 4 times to ensure that the simulation results really converged with a deviation of below $1 \%$ for each repetition.

\subsubsection{Static Vertical Bending Test Result}

The final result shown as follow:

- Max. Stress : $3.10982 \times 107 \mathrm{~N} / \mathrm{m}^{2}$

- Max. Displacement : 1.606 x $10^{-4} \mathrm{~m}$

- Safety Factor

$: 7.72$

\subsection{Torsional Stiffness Test}

\subsubsection{Torsional Load}

In the torsional stiffness test calculation, the load is located on the legs of the vehicle as presented in Fig. 7.

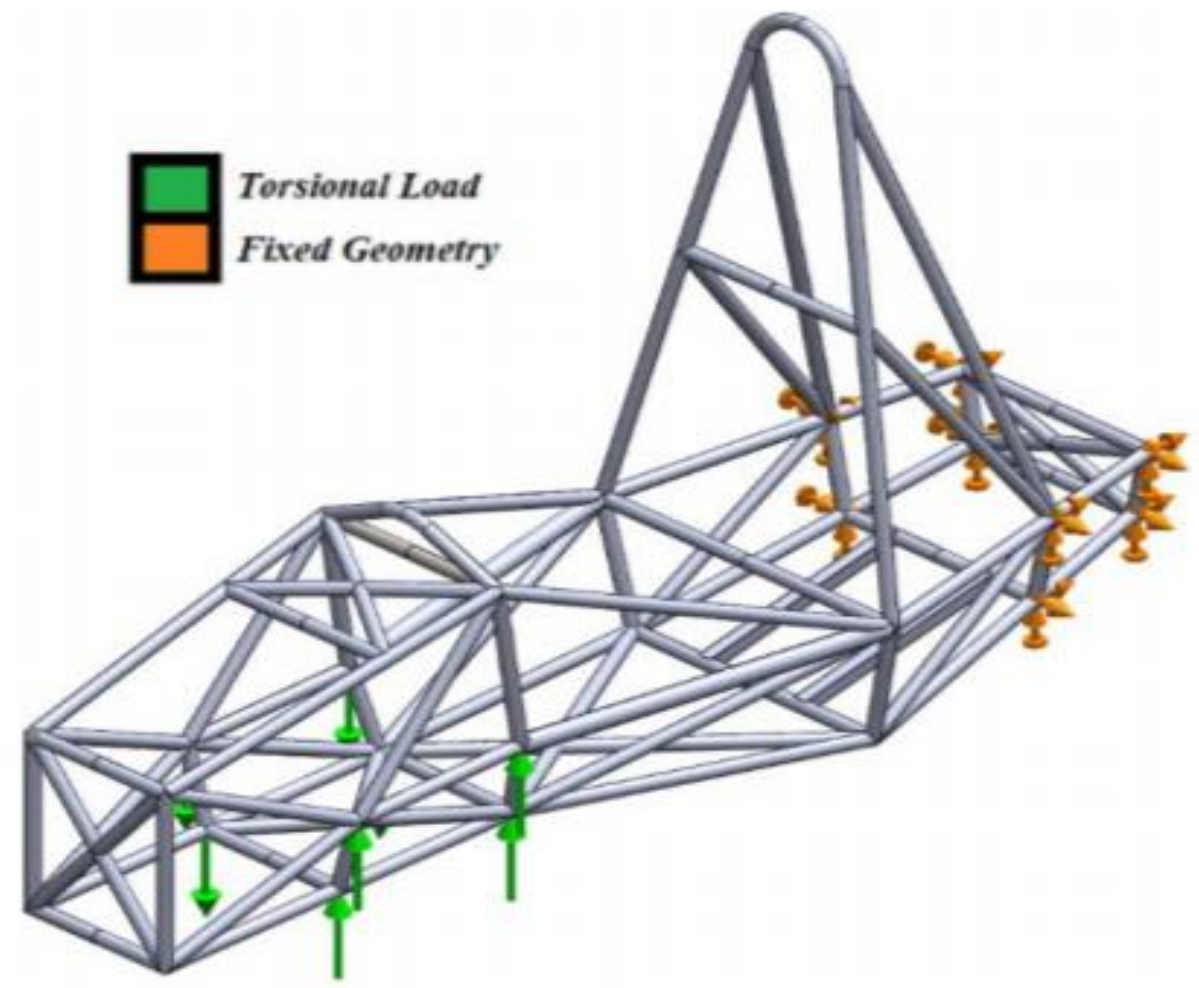

Fig. 7. Load and Fixed Position of Torsional Stiffness Test

With a frame mass of $48.9 \mathrm{~kg}$, the total mass of the vehicle can be estimated by adding up the mass of the frame, driver, and the components assumed in the Static Vertical Load calculation, plus the weight of the components outside the frame such as tires of $20 \mathrm{~kg}$. Thus, the total vehicle weight is:

$$
m=48.9+205+20 \mathrm{~kg}
$$

With a total mass of $308.9 \mathrm{~kg}$, the torsional load and the impact load can be calculated. The amount of torsional load can be calculated is:

$$
F=(273.9)(3)(9.8)=8052 \mathrm{~N}
$$

Assuming the load distribution is $50-50 \%$, the load to be input is $4026 \mathrm{~N}$. In the Torsional Stiffness Test calculation, the load is located on the legs of the vehicle. 
The mesh convergency is carried out by using a sample of the frame that has maximum stress from the simulation results by meshing automatically. The location of mesh convergency similar to Fig. 6.

The mesh size of the sample where the critical stress occurs is regulated in order to obtain a convergent maximum stress (max. Stress). The results of the mesh convergence test can be seen in the following Table 5:

Table 5: Torsional stiffness test mesh convergency

\begin{tabular}{ccccc}
\hline $\begin{array}{c}\text { Mesh Number } \\
(\mathbf{n})\end{array}$ & $\begin{array}{c}\text { Elapsed Time } \\
(\mathbf{s})\end{array}$ & $\begin{array}{c}\text { Total } \\
\text { Elements }\end{array}$ & $\begin{array}{c}\text { Max. Stress } \\
\left(\mathbf{N} / \mathbf{m}^{2}\right)\end{array}$ & \% Dev. \\
\hline 5 & 14 & 546 & $1.59201 \times 10^{8}$ & - \\
10 & 14 & 551 & $1.59215 \times 10^{8}$ & 0.001 \\
20 & 15 & 561 & $1.59232 \times 10^{8}$ & 0.011 \\
40 & 16 & 580 & $1.59272 \times 10^{8}$ & 0.026 \\
\hline
\end{tabular}

Repetitions were carried out 4 times to ensure that the simulation results really converged with a deviation of below $1 \%$ for each repetition.

\subsubsection{Torsional Stiffness Test Result}

The final result shown as follow:

- Max. Stress : $1.59272 \times 108 \mathrm{~N} / \mathrm{m}^{2}$

- Max. Displacement : $3.2 \times 10^{-3} \mathrm{~m}$

- Safety Factor $\quad: 1.51$

Maximum displacement $(\Delta y)$ will be used to get the torsional stiffness $(\mathrm{K})$ value defining using Equation 5:

$$
K=\frac{(4026)(0.2)}{\tan ^{-1}\left(\frac{0.0032+0.0032}{2(0.2)}\right)}=878.411 \mathrm{Nm} / \text { degree }
$$

With a torsional stiffness value of $878,411 \mathrm{Nm} / \mathrm{deg}$, the frame structure has a fairly high level of stiffness. Force moment of $878,411 \mathrm{Nm}$ needed to twist the frame by 1 degree.

\subsection{Crash Impact Test}

\subsubsection{Crash Impact Load}

In the Crash Impact Load calculation, the input data needed is velocity. The frame will be given a speed of $50 \mathrm{~km} / \mathrm{h}(17.89 \mathrm{~m} / \mathrm{s})$ in this simulation. However, because the weight of the frame recorded in the Abaqus software is $48.9 \mathrm{~kg}$, while the overall car weight is $273.9 \mathrm{~kg}$. therefore, the speed will be manipulated in such a way that the kinetic energy that will be stored by the frame before the collision will be the same as the kinetic energy that will be stored by the car. To calculate how much speed will be entered into the software, it is necessary to first calculate the kinetic energy stored by the car using Equation 6, becomes:

$$
E_{k}=\frac{(273.9)(17.89)^{2}}{2}=19072.05 \mathrm{~J}
$$

It should be noted that according to the 2019 FSAE regulations in point T.2.25.2, a car is required to have an impact attenuator on the front frame that can absorb the kinetic energy of at least 7350 Joules. So that for the simulation to run according to field conditions, the calculated kinetic energy needs to be reduced by the amount of energy that can be absorbed by 
the impact attenuator. Then the kinetic energy to be received by the frame is 19072.05 Joule. Thus, the velocity that will be entered into the software is:

$$
v=\sqrt{\frac{(2)(19072.05)}{(48.9)}}=27.93 \mathrm{~m} / \mathrm{s}
$$

\subsubsection{Crash Impact Test Result}

The final result shown in Fig. 8 with following data extracted:

- Max. Stress $: 3.132 \times 10^{8} \mathrm{~N} / \mathrm{m}^{2}$

- Max. Displacement : $0.107 \mathrm{~m}$

- Safety Factor $\quad: 1.27$

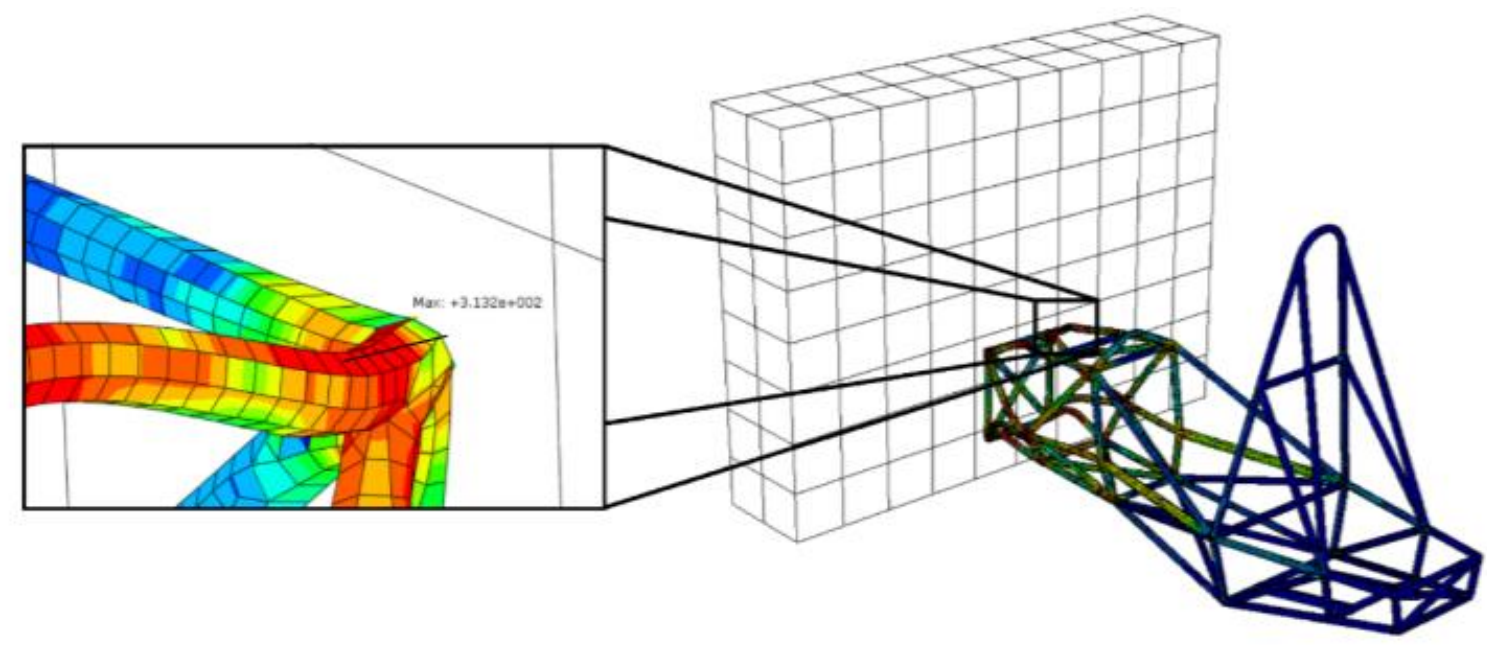

Fig. 8. Impact test

From the data above, it can be seen that the frame that is given a load is assumed to have a max. stress of $3,132 \times 108 \mathrm{~N} / \mathrm{m} 2$ so that it has a safety factor above $1(\mathrm{Sf} \geq 1)$, with a number of 1.27 for ultimate stress, which means that the frame has undergone plastic deformation but has not yet broken or broken. The displacement size on the frame is quite large, $0.107 \mathrm{~m}$ or $10.7 \mathrm{~cm}$ which occurs where the gas and brake pedals are installed so that it has the potential to injure the driver's feet. The injury to the driver needs to be recalculated to ensure the level of injury. However, in plain view, it can be ascertained that the injury that will be experienced by the driver is a minor one because the frame is still intact and there is no extreme displacement.

\section{CONCLUSION}

An optimum frame design based on FSAE Japan regulations obtained with dimensions of $1945 \times 660 \times 1320 \mathrm{~mm}$ and a mass of $48.9 \mathrm{~kg}$. After going through 3 kinds of simulations, the designed frame got a safety factor of 7.72 on the Static Vertical Bending Test, 1.51 in the Torsional Stiffness Test, and 1.27 in the crash impact test so that the design of this frame can be said to be safe to use.

\section{ACKNOWLEDGEMENT (ACKNOW)}

Thanks to Universitas Sriwijaya to facilities this research. 


\section{REFERENCES}

[1] G. Broadbent and G. Metternicht. (2019, 15 September 2019). How does Shorten's electric vehicle sales target stack up? Available: https://newsroom.unsw.edu.au/news/science-tech/howdoes-shortens-electric-vehicle-sales-target-stack

[2] G. Milev, A. Hastings, and A. Al-Habaibeh, "The environmental and financial implications of expanding the use of electric cars - A Case study of Scotland," Energy and Built Environment, vol. 2, no. 2, pp. 204-213, 2021.

[3] I. Malmgren, "Quantifying the Societal Benefits of Electric Vehicles," World Electric Vehicle Journal, vol. 8, no. 4, pp. 996-1007, 2016.

[4] T. Chawla and E. C. Leonhardt, "Two Approaches to Optimize Formula SAE Chassis Design Using Finite Element Analysis," 2018.

[5] M. Pasa, I. Dumitru, L. Matei, L. J. A. M. Racim , and Materials, "Development and Analysis of a Frame for Formula Student Competition," vol. 896, pp. 105 - 112, 2020.

[6] T. Limwathanagura, C. Sithananun, T. Limchamroon, T. J. W. A. o. S. Singhanart, Engineering, I. J. o. M. Technology, Aerospace, Industrial, Mechatronic, and M. Engineering, "The Frame Analysis and Testing for Student Formula," vol. 6, pp. 998-1002, 2012.

[7] H. Hazimi, U. Ubaidillah, R. Alnursyah, H. Nursya bani, B. W. Lenggana, and Wibowo, "Improvement of Space Tube Frame for Formula Student Vehicle," 2020.

[8] N. Chandan S, N. Vinayaka, M. J. I. j. o. e. r. SandeepG, and technology, Design, Analysis and Optimization of Race Car Chassis for its Structural Performance. 2016.

[9] J. K. Nisbett and R. G. Budynas, Shigley's Mechanical Engineering Design, 10th edition ed. McGraw-Hill Education, 2014.

[10] T. Singhanart, T. Sangmanacharoen, W. Tocharoen, and P. Danwibun, "Space Frame Analysis, Design, and Testing for Electric Vehicle Formula," Applied Mechanics and Materials, vol. 619, pp. 183-187, 2014.

[11] A. Ghosh, R. Saha, S. Dhali, A. Das, P. Biswas, and A. K. Dubey, "Structural Analysis of Student Formula Race Car Chassis," vol. 05, no. 12, pp. 1268-1273, 2018. 